\title{
Macrophage migration inhibitory factor promotes cardiac stem cell proliferation and endothelial differentiation through the activation of the PI3K/Akt/mTOR and AMPK pathways
}

\author{
JINJIN CUI ${ }^{1,2}$, FENGYUN ZHANG ${ }^{1,2}$, YONGSHUN WANG ${ }^{1,2}$, JINGJIN LIU $^{1,2}$, XING MING $^{1,2}$,

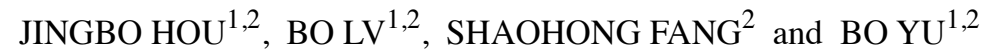 \\ ${ }^{1}$ Department of Cardiology, The Second Affiliated Hospital of Harbin Medical University; \\ ${ }^{2}$ The Key Laboratory of Myocardial Ischemia, Chinese Ministry of Education, Harbin, Heilongjiang 150081, P.R. China
}

Received July 31, 2015; Accepted March 16, 2016

DOI: $10.3892 / \mathrm{ijmm} .2016 .2542$

\begin{abstract}
Macrophage migration inhibitory factor (MIF) has pleiotropic immune functions in a number of inflammatory diseases. Recent evidence from expression and functional studies has indicated that MIF is involved in various aspects of cardiovascular disease. In this study, we aimed to determine whether

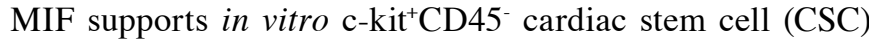
survival, proliferation and differentiation into endothelial cells, as well as the possible mechanisms involved. We observed MIF receptor (CD74) expression in mouse CSCs (mCSCs) using PCR and immunofluorescence staining, and MIF secretion by mCSCs using PCR and ELISA in vitro. Increasing amounts of exogenous MIF did not affect CD74 expression, but promoted mCSC survival, proliferation and endothelial differentiation. By contrast, treatment with an MIF inhibitor (ISO-1) or siRNA targeting CD74 (CD74-siRNA) suppressed the biological changes induced by MIF in the mCSCs. Increasing amounts of MIF increased the phosphorylation of Akt and mammalian target of rapamycin (mTOR), which are known to support cell survival, proliferation and differentiation. These effects of MIF on the mCSCs were abolished by LY294002 [a phosphoinositide 3-kinase (PI3K) inhibitor] and MK-2206 (an Akt inhibitor). Moreover, adenosine monophosphate-activated protein kinase (AMPK) phosphorylation increased following treatment with MIF. The AMPK inhibitor, compound C, partly blocked the pro-proliferative effects of MIF on the mCSCs. In conclusion, our results suggest that MIF promotes mCSC survival, proliferation and endothelial differentiation through the activation of the $\mathrm{PI} 3 \mathrm{~K} / \mathrm{Akt} / \mathrm{mTOR}$ and AMPK signaling pathways. Thus, MIF may prove to be a potential therapeutic factor in the treatment of heart failure and myocardial infarction by activating CSCs.
\end{abstract}

Correspondence to: Dr Bo Yu, Department of Cardiology, The Second Affiliated Hospital of Harbin Medical University, 157 Baojian Road, Nangang, Harbin, Heilongjiang 150081, P.R. China

E-mail: dryu_hmu@163.com

Key words: macrophage migration inhibitory factor, cardiac stem cells, proliferation, endothelial differentiation, PI3K/Akt/mTOR

\section{Introduction}

To date, stem/progenitor cell-based therapies are promising therapeutic approaches for the treatment of various heart diseases, including ischemic heart disease and heart failure. These cells promote angiogenesis and endogenous stem cell activation, and exert anti-apoptotic effects on surviving cardiomyocytes through paracrine signaling, resulting in improved cardiac function (1-3). Two potential adult stem cell sources are cardiac stem cells (CSCs) isolated from the heart itself and bone marrow-derived mesenchymal stem cells (BM-MSCs), and each has been implicated in contributing to the restoration of cardiac function $(4,5)$. Previous evidence has suggested that CSCs have greater cardioprotective potential in ischemic heart failure compared to BM-MSCs (6) and are necessary and sufficient for anatomical and functional adult myocardial regeneration following severe diffuse myocardial damage (7). Nonetheless, aging, ischemic myocardial injury, cardiac hypertrophy and metabolic disorders, together with environmental factors, can markedly affect resident human CSC (hCSC) growth and differentiation (8-11).

Macrophage migration inhibitory factor (MIF) is a proinflammatory factor that participates in the pathogenesis of various inflammatory diseases, including sepsis, atherosclerosis and rheumatoid arthritis (12-14). It is produced and stored in various cell types, including immune cells, endothelial cells and cardiomyocytes. It is then rapidly released from intracellular stores in response to various noxious stimuli, such as infection, inflammation and hypoxia (15-17). Increasing evidence has demonstrated that MIF protects the heart following ischemia/reperfusion ( $\mathrm{I} / \mathrm{R})$ by activating adenosine monophosphate-activated protein kinase (AMPK), inhibiting c-Jun $\mathrm{N}$-terminal kinase (JNK)-mediated apoptosis, and attenuating cardiomyocyte oxidative stress, thereby reducing the infarct size and preserving cardiac function $(18,19)$. However, it is unknown whether MIF protects the injured heart in other ways, such as by activating resident CSCs and promoting their survival, proliferation and/or differentiation into myocytes and coronary vessels.

CD74 was initially considered a major histocompatability complex class II chaperone (20). However, it was later found to be an MIF receptor, and it can form a complex with CD44 (21). In 
studies on other types of stem cells, MIF was shown to promote stem/progenitor cell survival and proliferation by increasing Akt, extracellular signal-regulated kinase ERK) and AMPK phosphorylation, and to regulate CD74-dependent cell migration (22-24). Recently, some researchers reported that MIF protected BM-MSCs from senescence through Akt signaling $(25,26)$. The phosphoinositide 3-kinase (PI3K)/Akt/mammalian target of rapamycin (mTOR) signaling pathway has been shown to play a central role in several cellular functions, including survival, proliferation, adhesion, migration, differentiation and metabolism (27-29). However, whether MIF can affect CSCs through CD74 and the PI3K/Akt/mTOR signaling pathway and AMPK activition remains unknown.

In this study, we addressed two questions: i) whether MIF promotes CSC survival, proliferation and endothelial differentiation, and ii) whether the effects of MIF on CSCs are mediated through the PI3K/Akt/mTOR and AMPK signaling pathways and interactions with the CD74 receptor. Our results demonstrate that MIF may be a potential therapeutic factor in the treatment of degenerative heart disorders, as it is able to activate CSCs.

\section{Materials and methods}

Animals. BALB/c mice, weighing 18-25 g, were used for the cell isolation and culture experiments. All BALB/c mice were purchased from the Laboratory Animal Science Department, the Second Affiliated Hospital of Harbin Medical University, Heilongjiang, China. All experiments were carried out in accordance with the Local Ethics Committee of Harbin Medical University Animal Care and Use.

CSC isolation and identification. Mouse CSCs were obtained as described previously, with a minor modification $(30,31)$. Briefly, mice were sacrificed by cervical dislocation, the heart tissue was chopped, followed by enzymatic dissociation. The hybrid cells were then isolated using an FITC rat anti-mouse CD117/c-kit antibody (561680; BD Biosciences, Franklin Lakes, NJ, USA) and MACS anti-FITC microbeads (130-048-701; Miltenyi Biotec, Bergisch Gladbach, Germany) for positive sorting. These obtained cells were subjected to negative selection with PE rat anti-mouse CD45 antibody (561087; BD Biosciences, Franklin Lakes, NJ, USAs) and MACS anti-PE microbeads (130-048-801; Miltenyi Biotec). The cells were cultured in HyClone Dulbecco's modified Eagle's medium (DMEM)/F12 (Thermo Fisher Scientific, Waltham, MA, USA) supplemented with $10 \%$ fetal bovine serum (FBS), basic fibroblast growth factor (bFGF; $10 \mathrm{ng} / \mathrm{ml}$; 100-18B), insulin-like growth factor (IGF; $10 \mathrm{ng} / \mathrm{ml} ; 250-19$ ), epidermal growth factor (EGF; $10 \mathrm{ng} / \mathrm{ml} ; 100-15)$ and leukemia inhibitory factor (LIF; $10 \mathrm{ng} / \mathrm{ml} ; 300-05$ ) (all from Peprotech, Rocky Hill, NJ, USA), at $37^{\circ} \mathrm{C}$ in $5 \% \mathrm{CO}_{2}$. All cells used in the subsequent experiments were between passages 3 and 5 .

To identify surface markers, the cells at passages 3-5 were harvested, washed with phosphate-buffered saline (PBS), and labeled with the following conjugated antibodies: FITC-labeled anti-CD CD117 (561680; BD Biosciences, Franklin Lakes, NJ, USA), anti-CD45 (11-0451-82; eBioscience, San Diego, CA, USA), anti-CD29 (561796), anti-CD34 (560238), and phycoerythrin-labeled anti-Sca-1 (561076), APC-labeled anti-CD90 (561974), PE-labeled anti-CD31 (561073) and anti-KDR
(561259) antibodies (all from BD Biosciences, Franklin Lakes, NJ, USA). The labeled cells were analyzed by flow cytometry using FACSDiva Pro Software (Becton-Dickinson, San Jose, CA, USA).

In addition, the thymus and liver samples of the mice sacrificed to obtain the CSCs were preserved in liquid nitrogen as a positive control for the PCR experiment for examining MIF and CD74. BM-MSCs were purchased from the Americal Type Culture Collection (ATCC; Manassas, VA, USA) and also used as a positive control. BM-MSCs were cultured in LG-DMEM (HyClone, Logan, UT, USA), supplemented with $10 \%$ fetal calf serum (FCS; HyClone), at $37^{\circ} \mathrm{C}$ in $5 \% \mathrm{CO}_{2}$.

Cell treatment. In preliminary experiments, a time course analysis was performed in which the cells were incubated with various concentrations $(0,50,100$ and $200 \mathrm{ng} / \mathrm{ml})$ of MIF (1978-MF-025; R\&D Systems, Chantilly, VA, USA) for 0,24 or $48 \mathrm{~h}$. In subsequent experiments, the optimal MIF concentration $(200 \mathrm{ng} / \mathrm{ml})$ was incubated with the mCSCs for the indicated period of time $(0,30,60,90,120$ and $180 \mathrm{~min})$ in complete medium without growth factors. In blockade assays, ISO-1 (an MIF inhibitor; $100 \mu \mathrm{g} / \mathrm{ml} ; 475837$; Calbiochem, San Diego, CA, USA), LY294002 (a PI3K inhibitor; $25 \mu \mathrm{M}$; L9908; Sigma, St. Louis, MO, USA), MK-2206 (an Akt inhibitor; $3 \mu \mathrm{M}$; S1078; Selleckchem, Houston, TX, USA), or compound C (an AMPK inhibitor; $40 \mu \mathrm{M}$; 171260; Merck, Darmstadt, Germany) was added to the medium. The inhibitors were pre-incubated with the cells in complete medium for 90 min prior to exposure to MIF as previously described (32). For determining whether the isolated cells can differentiate into 3 main cardiac lineages, the CSCs at passage 3-5 were placed in differentiation medium containing DMEM, 10\% FBS and $10^{-8} \mathrm{M}$ dexamethasone or $10 \mathrm{M}$ 5-Azacytidine for $24 \mathrm{~h}$. Following this procedure, the cells were maintained in $2 \%$ FBS medium with or without dexamethasone for 21 days.

Knockdown experiments using small interfering RNA (siRNA). The following sequences of mouse-specific siRNA targeting CD74 (CD74-siRNA), 5'-CCAGGACCAUGUGAUGCA UTT-3' and negative control siRNA (NC-siRNA) 5'-UUCU CCGAACGUGUCACGUTT-3' were used for gene silencing experiments. Single cells were seeded in 6- or 96-well plates, and siRNA constructs were transfected at a concentration of 80 nM using X-tremeGENE siRNA Transfection Reagent (Roche Applied Science, Penzberg, Germany) according to the manufacturer's instructions. The siRNA-CD74 knockdown efficiency was determined by western blot analysis.

RNA extraction and reverse transcription-quantitative $P C R(R T-q P C R)$. Total RNA was isolated from the cultured cells using TRizol reagent (Invitrogen, Shanghai, China) and reverse transcribed into cDNA using AccuPower ${ }^{\circledR}$ RocketScript $^{\mathrm{TM}}$ RT PreMix (Bioneer, Shanghai, China) according to the manufacturer's instructions. RT-qPCR was performed using AcccuPower ${ }^{\circledR}$ 2X Greenstar qPCR master mix (Bioneer) and the ABI fluorescence quantitative PCR system (Bio-Rad, Hercules, CA, USA). The PCR conditions were as follows: 1 cycle of $10 \mathrm{~min}$ at $95^{\circ} \mathrm{C}$, followed by 40 cycles of $95^{\circ} \mathrm{C}$ for $30 \mathrm{sec}, 60^{\circ} \mathrm{C}$ for $30 \mathrm{sec}$, and $72^{\circ} \mathrm{C}$ for $60 \mathrm{sec}$. Relative gene expression levels were calculated using the $2^{-\Delta \Delta C t}$ method, as previously described (32). Glyceraldehyde 
Table I. Primer sequences used for RT-qPCR.

\begin{tabular}{ll}
\hline Genes & \multicolumn{2}{c}{ Sequences } \\
\hline CD74 & F: 5'-ACGCGACCTCATCTCTAACC-3' \\
& R: 5'-GGTCATGTTGCCGTACTTGG-3' \\
GAPDH & F: 5'-AGGTCGGTGTGAACGGATTTG-3' \\
& R: 5'-TGTAGACCATGTAGTTGAGGTCA-3'
\end{tabular}

GAPDH, glyceraldehyde 3-phosphate dehydrogenase; F, forward; $\mathrm{R}$, reverse.

3-phosphate dehydrogenase (GAPDH) mRNA levels were used as internal normalization controls. For semi-quantitative PCR, the PCR products were resolved on a $2 \%$ agarose gel stained with Dured nucleic acid dye (Fanbo Biochemicals, Beijing, China). Primer pairs used to detect target gene mRNA levels are listed in Table I.

Cell proliferation assay. Cell survival/proliferation was assessed using a CCK-8 assay (Beyotime Institute of Biotechnology, Shanghai, China) according to the manufacturer's instructions. Cells in a 96-well plate were incubated with CCK-8 for $2 \mathrm{~h}$ at $37^{\circ} \mathrm{C}$. Absorbance of each well was measured at $450 \mathrm{~nm}$.

In 5-ethynyl-2'-deoxyuridine (EdU) chase experiments, the CSCs were seeded into 96-well plates at a density of $1-2 \times 10^{3}$ cells $/ \mathrm{ml}$ and cultured in serum-free medium for $24 \mathrm{~h}$. The cells were then treated with MIF for $24 \mathrm{~h}$ in complete culture medium and EdU (RiboBio, Guangzhou, China) was added to a final concentration of $50 \mu \mathrm{M}$ for a further $2 \mathrm{~h}$. The cells were fixed with $4 \%$ paraformaldehyde (PFA) for $30 \mathrm{~min}$, permeabilized with PBS containing $0.5 \%$ Triton X-100 for 10 min and stained with $1 \mathrm{X}$ Apollo ${ }^{\circledR}$ reaction cocktail for $30 \mathrm{~min}$, followed by staining with Hoechst 33342 for $30 \mathrm{~min}$ at room temperature. At least 10 different viewing fields were counted for analysis. All images were obtained using a fluorescence microscope (Leica DM4000B; Leica, Solms, Germany).

For cell cycle analysis, the mCSCs were treated with MIF (200 ng/ml) for $48 \mathrm{~h}$, then harvested and washed with PBS, and fixed with $75 \%$ ethanol overnight. The cells were then washed with PBS and incubated with RNase A $(20 \mathrm{mg} / \mathrm{ml})$ for $30 \mathrm{~min}$ at $37^{\circ} \mathrm{C}$. This was followed by a further incubation with propidium iodide (PI, $0.5 \mathrm{mg} / \mathrm{ml}$ ) for $30 \mathrm{~min}$ at $4^{\circ} \mathrm{C}$. Finally, the cells were washed and resuspended in $500 \mu \mathrm{l}$ of PBS, then analyzed using a Becton-Dickinson flow cytometer (BD Biosciences, Franklin Lakes, NJ, USA) to detect the DNA content.

Western blot analysis. Western blot analysis was performed as previously described (33). Briefly, cells were washed in ice-cold PBS and lysed in RIPA buffer $(50 \mathrm{mM}$ Tris- $\mathrm{HCl}, 150 \mathrm{mM} \mathrm{NaCl}$, $1 \%$ Triton $\mathrm{X}-100,1 \%$ sodium deoxycholate and $0.1 \%$ SDS, $\mathrm{pH}$ 7.6) (Beyotime Institute of Biotechnology) containing protease and phosphatase inhibitors (cocktail tablet; Roche Applied Science). The lysates were centrifuged at 12,000 x g for $15 \mathrm{~min}$ at $4^{\circ} \mathrm{C}$, and supernatants were collected. The protein concentrations of each sample were determined with a BCA protein assay kit (Beyotime Institute of Biotechnology) according to the manufacturer's instructoins. Equal amounts of proteins were electrophoresed on $10 \%$ sodium dodecyl sulfatepolyacrylamide gel electrophoresis (SDS-PAGE) gels and transferred onto polyvinylidene fluoride (PVDF) membranes (Beyotime Institute of Biotechnology). The membranes were blocked with 5\% skim milk in Tris-buffered saline containing $0.1 \%$ Tween-20 (TBST) at room temperature for $1 \mathrm{~h}$, then incubated overnight at $4^{\circ} \mathrm{C}$ with the following primary antibodies: Akt (1:1,000; 4691), phospho-Akt (Thr308; 1:750; 4056), mTOR (1:1,000; 2983), phospho-mTOR (Ser2448; 1:750; 2971), AMPK (1:1,000; 5831s), phospho-AMPK (Thr172; 1:750; 4188) (all from Cell Signaling Technology, Danvers, MA, USA), CD74 (1:100; sc-5438), vascular endothelial growth factor (VEGF; 1:200; sc-507), von Willebrand factor (vWF; 1:200; sc-14014) (all from Santa Cruz Biotechnology, Inc., Santa Cruz, CA, USA) and GAPDH (1:1,000; AB-P-R 001; Good Here Biochemicals, Hangzhou, China). The membranes were washed in TBST and incubated with the appropriate horseradish peroxidase (HRP)-conjugated secondary antibodies (1:5,000, goat anti-rabbit; ZDR-5306; Zhongshan Golden Bridge Biotechnology, Beijing, China) for $1 \mathrm{~h}$ at room temperature. Signals were detected with an ECL-Plus Substrate (P0018; Beyotime Institute of Biotechnology) and exposed to Hyper film (Kodak, Rochester, NY, USA), and quantified and analyzed using Quantity One software (Bio-Rad).

Immunofluorescence staining. For identifying the isolated cells, cells at passages 3-5 were seeded onto 48-well plates and fixed with $4 \%$ PFA for $30 \mathrm{~min}$ at room temperature, permeabilized with $0.5 \%$ Triton X-100, blocked with $1 \%$ BSA and incubated with rabbit anti-c-kit (stemness marker; sc-168), antiNK2 homeobox 5 (Nkx2.5; sc-14033) and anti-GATA binding protein 4 (GATA-4; sc-9053) (cardiac lineage markers) (1:50; Santa Cruz Biotechnology, Inc.) antibodies at $4^{\circ} \mathrm{C}$ overnight. After washing, the cells were incubated with TRITC- or FITCconjugated AffiniPure goat anti-rabbit $\operatorname{IgG}(\mathrm{H}+\mathrm{L})$ antibodies, TRITC-conjugated AffiniPure goat anti-mouse IgG $(\mathrm{H}+\mathrm{L})$ antibodies (1:50; ZF-0316, ZF-0311, ZF-0313; Zhongshan Golden Bridge Biotechnology) for $1 \mathrm{~h}$ at room temperature. The nuclei were stained with 4',6-diamidino-2-phenylindole (DAPI; D8417; Sigma). Fluorescent images were acquired using a fluorescence microscope (Leica DMI4000B). To examine CD74 expression in the CSCs, rabbit anti-CD74 antibody (1:50; sc-5438; Santa Cruz Biotechnology, Inc.) was used. The CSCs used in the endothelial differentiation experiments were stained with rabbit anti-VEGF (1:50; sc-507) and rabbit anti-vWF (1:50; sc-14014; Santa Cruz Biotechnology, Inc.) antibodies. To identify the differentiation of CSCs into myocardial cells or smooth muscle cells, mouse anti-TnI (1:100; ab19615; Abcam, Cambridge, MA, USA) and mouse anti-SMA (1:100, BM0002; Boster, Wuhan, China) were used.

Tube formation assay. To measure tube formation, 48-well plates were coated with Matrigel (BD Biosciences, Bedford, MA, USA) according to the manufacturer's instructions. Human umbilical vein endothelial cells (HUVECs) were purchased from ATCC and cultured in DMEM-1640 and endothelial cells (ECs) differentiated from the CSCs (CSC-ECs) in DMEM/F12 supplemented with $0.2 \%$ FBS were seeded on Matrigel-coated plates $\left(1.5 \times 10^{4}\right.$ cells/well) and incubated for $4 \mathrm{~h}$ at $37^{\circ} \mathrm{C}$. Subsequently, capillary-like structures were 
A

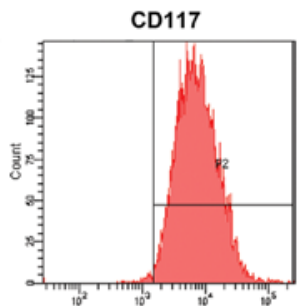

CD29

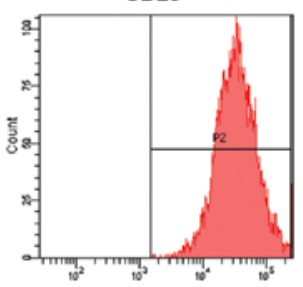

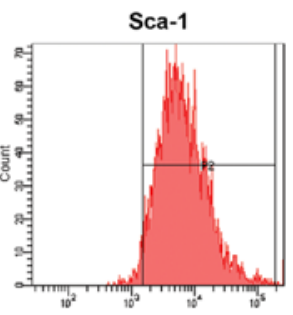

CD45

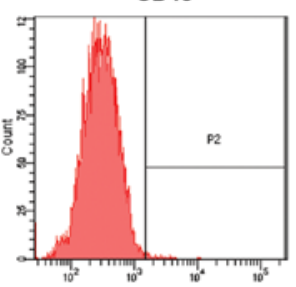

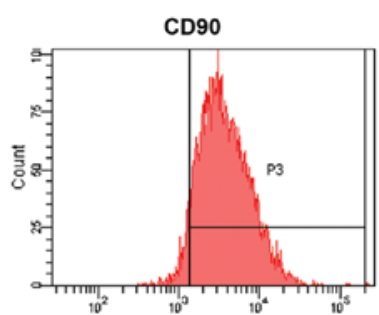

CD31

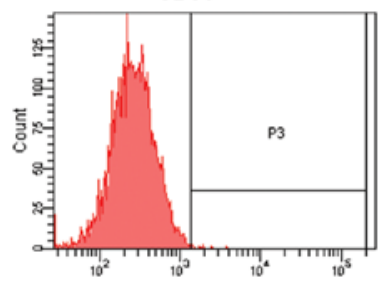

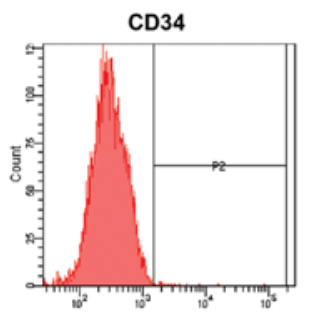

KDR

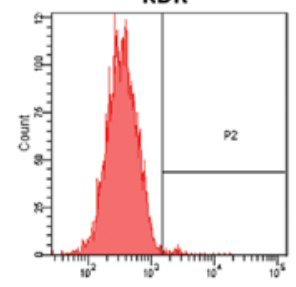

B
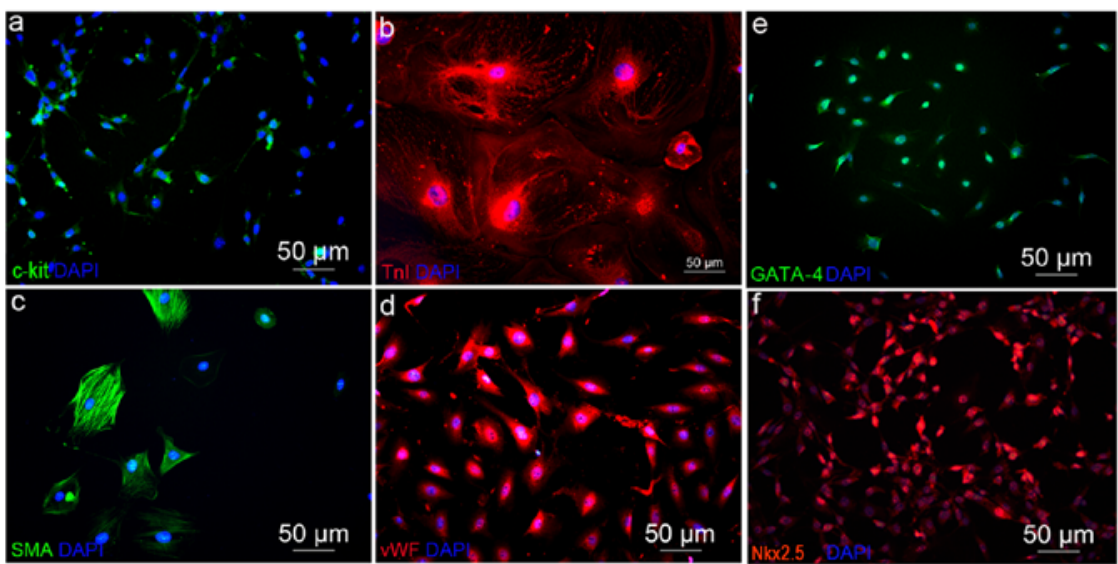

Figure 1. Identification of isolated cells. (A) As shown by flow cytometry analysis, at passage 3 (P3) after sorting, the c-kit-positive cells reached $93.4 \pm 0.95 \%$,

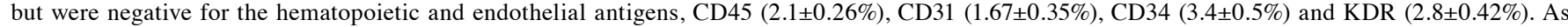
expected, they were positive for the control mesenchymal markerS, CD90 (71.6 $\pm 1.55 \%)$, CD29 (93.7 $\pm 1.2 \%)$, and THYE stemness marker Sca-1 (82.33 $\pm 0.90 \%)$. (B) Immunofluorescence staining of the main cardiac lineages differentiated from c-kit ${ }^{+}$cells, namely (panel b) the cardiomyocyte marker, TnI; (panel c) the smooth muscle cell marker, SMA; and (panel d) the endothelial cell marker, vWF. The expression of the cardiac lineage markers (panel e) GATA-4; and (panel f) Nkx2.5 in the c-kit ${ }^{+}$cells was also analyzed. Nuclei were counterstained with DAPI.

observed and were quantified by calculating the number of junctions per field; at least 5 different viewing fields were analyzed. All images were obtained using an inverted microscope (Olympus IX73; Olympus, Tokyo, Japan).

MIF enzyme-linked immunosorbent assay (ELISA). A mouse MIF ELISA kit (BlueGene, Shanghai, China) was used to measure the amount of secreted MIF in the culture supernatants. The assays were conducted in 96-well microplates according to the manufacturer's instructions.

Statistical analysis. All values are expressed as the means \pm standard deviation (SD). The statistical differences between 2 groups was determined using a Student's t-test, and differences among groups were examined by one-way ANOVA with the statistical software SPSS package v19.0 (IBM Corp., Armonk, NY, USA). A value of $\mathrm{p}<0.05$ was considered to indicate a statistically significant difference.

\section{Results}

Cells isolated from mouse hearts exhibit CSC characteristics. FACS analysis revealed that the majority of cells from passages 3-5 expressed common surface markers for CSCs: they were positive for c-kit $(93.4 \pm 0.95 \%)$, Sca-1 $(82.33 \pm 0.90 \%)$, CD90 (71.6 $\pm 1.55 \%)$ and CD29 (93.7 $\pm 1.2 \%)$, but negative for

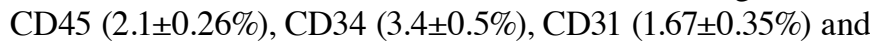
KDR $(2.8 \pm 0.42 \%)$ (Fig. 1). In addition, immunofluorescence staining revealed that these cells were positive for c-kit, $\mathrm{Nkx} 2.5$ and GATA-4, and positive for troponin I (TnI), smooth muscle actin (SMA) and vWF following treatment with dexamethasone or 5-Azacytidine (Fig. 1). These data suggest that the cells used in our experiments were stem cells of cardiac origin.

MIF and MIF receptor CD74 expression in CSCs. It has previously been demonstrated that MIF is a ligand of CD74 which can activate various signaling pathways in various cell types, including stem/progenitor cells (22). Another study demonstrated that cardiac-derived MIF enhances post-ischemic injury myocardial healing by protecting cardiomyocytes from apoptosis (34). Therefore, we hypothesized that CSC-derived MIF can support CSC survival and proliferation through its interactions with CD74, which is expressed in CSCs. Thus, we first examined MIF and CD74 gene expression in CSCs using RT-PCR, and then we confirmed CD74 protein expression by immunofluorescence staining and the amount of secreted MIF from CSC superna- 

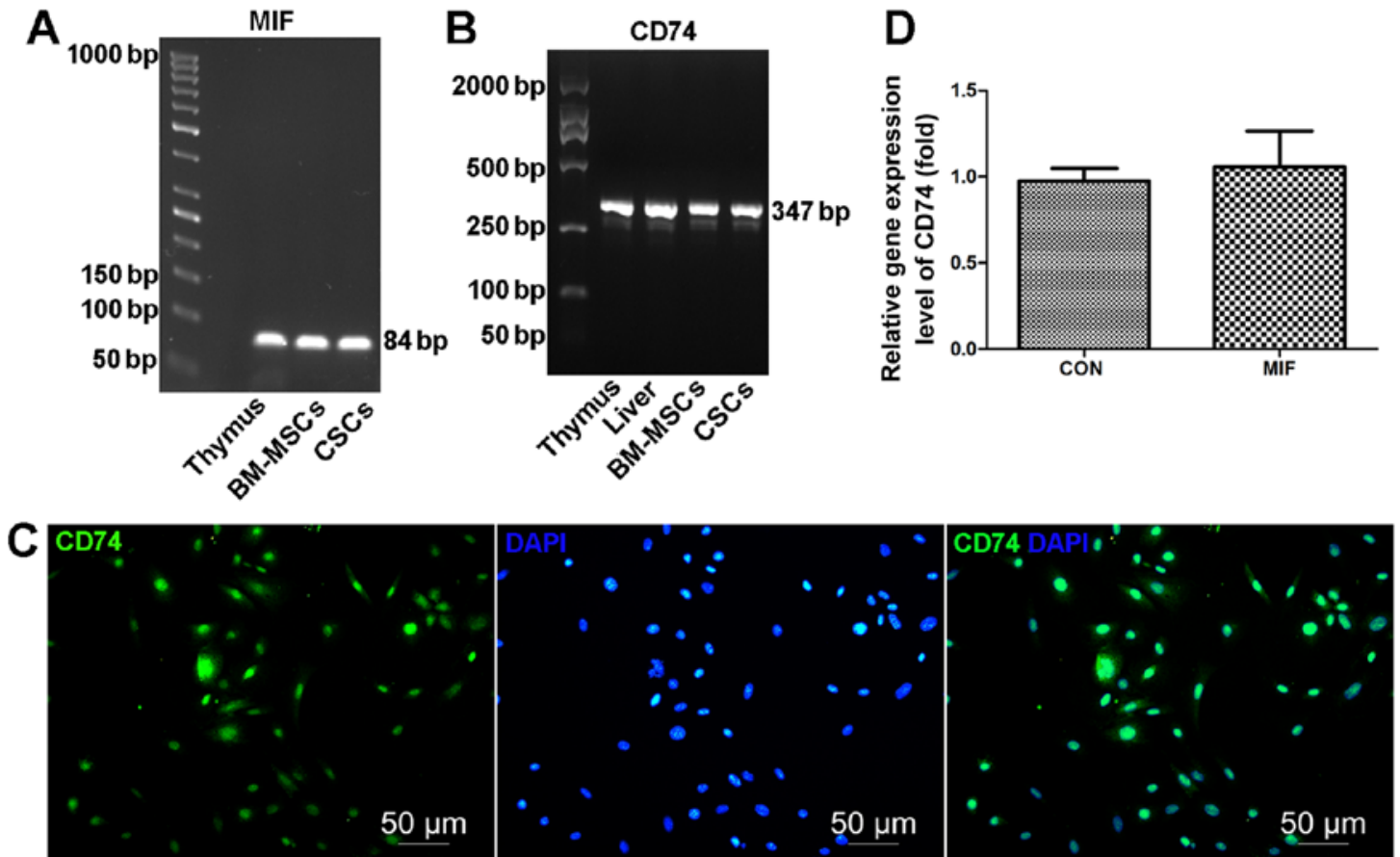

Figure 2. Macrophage migration inhibitory factor (MIF) and CD74 expression in cardiac stem cells (CSCs). (A and B) MIF and CD74 PCR products run on a $2 \%$ agarose gel. Thymus, liver and bone marrow-derived mesenchymal stem cells (BM-MSCs) were used as positive controls. (C) CD74 immunoreactivity (green) in cultured mouse CSCs. The merged image is also shown. (D) CD74 mRNA expression was analyzed by qRT-PCR before and after MIF stimulation. There was no statistical significance. Data are the means \pm SD of 3 independent experiments $(n=3)$.

tants by ELISA. We found that CSCs expressed MIF (Fig. 2A) and secreted MIF $\left(317.07 \pm 5.56 \mathrm{pg} / \mathrm{ml}\right.$ for $1-2 \times 10^{6} \mathrm{mCSCs}$ cultured in $5 \mathrm{ml}$ medium for $24 \mathrm{~h}$ ) (Fig. 2A) and expressed CD74 (Fig. 2B and C). In addition, co-culture with exogenous MIF had no effect on the CD74 mRNA levels (Fig. 2D).

Effects of MIF on CSC proliferation. To examine the effects of MIF on the CSCs, we evaluated the proliferation of MIF-treated cells using CCK-8 and EdU assays. The CCK-8 assay indicated that MIF significantly increased cell viability at day $1(100 \mathrm{ng} / \mathrm{ml}, 1.206 \pm 0.089$-fold compared to control, $\mathrm{p}<0.01, \mathrm{n}=3 ; 200 \mathrm{ng} / \mathrm{ml}, 1.173 \pm 0.098$-fold compared to control, $\mathrm{p}<0.05, \mathrm{n}=3)$ (Fig. 3A) and at day $2(100 \mathrm{ng} / \mathrm{ml}, 1.228 \pm 0.012$-fold compared to control, $\mathrm{p}<0.01, \mathrm{n}=3 ; 200 \mathrm{ng} / \mathrm{ml}, 1.431 \pm 0.036$-fold compared to control, $\mathrm{p}<0.01, \mathrm{n}=3$ ) (Fig. $3 \mathrm{~A}$ ). MIF at $50 \mathrm{ng} / \mathrm{ml}$ had no significant effect on cell viability (Fig. 3A). The optimal concentration of MIF selected for use in the subsequent experiments was $200 \mathrm{ng} / \mathrm{ml}$.

We further examined the effects of MIF on CSC proliferation by EdU assay and found increased EdU incorporation following treatment with MIF compared to the control (1.57 \pm 0.13 -fold compared to control, $\mathrm{p}<0.01$; $n=3$ ) (Fig. 3D and E). We then examined the effects of the MIF-specific inhibitor, ISO-1, on the CSCs and found that treatment with ISO-1 $(100 \mu \mathrm{g} / \mathrm{ml})$ decreased cell proliferation, as assessed by EdU assay $(0.67 \pm 0.05$-fold of control, 0.267 \pm 0.05 -fold of MIF, p $<0.01 ; n=3$ ) (Fig. 3D and E).

Cell cycle analysis also revealed that MIF increased the number of cells in the S-phase $(1.82 \pm 0.04$-fold of control, $\mathrm{p}<0.01 ; \mathrm{n}=3$ ) (Fig. 3B and C), and treatment with ISO-1 significantly decreased the population of cells in the S-phase (0.49 \pm 0.09 -fold of control, $0.43 \pm 0.04$-fold of MIF, $\mathrm{p}<0.01$; n=3) (Fig. 3B and C). Taken together, these data suggest that MIF promotes CSC proliferation.

MIF promotes CD74-dependent CSC proliferation. To determine whether CD74 is involved in the pro-proliferative effects of MIF on CSCs, we examined CSC proliferation following the knockdown of CD74 by siRNA. We confirmed a decrease in CD74 protein expression $(36.52 \pm 6.61 \%$ compared to control, $\mathrm{p}<0.01 ; \mathrm{n}=3$ ) (Fig. 4A and $\mathrm{B}$ ) by western blot analysis. Importantly, the results from EdU assay indicated that CD74 knockdown decreased the proliferation of the MIF-treated CSCs (Fig. 4E and F). Cell cycle analysis also revealed that CD74 knockdown in the CSCs markedly decreased the number of cells in the S-phase (Fig. 4C and D), which further supports our hypothesis that MIF promotes CSC proliferation through its interaction with CD74.

MIF activates the PI3K/Akt/mTOR signaling and AMPK pathways. The PI3K/Akt/mTOR axis intersects with a number of intracellular signaling pathways, and thus regulates many cellular events, including cell-cycle progression, proliferation/growth and angiogenesis (27). Therefore, in this study, we investigated whether these pathways mediate the pro-proliferative effects of MIF on CSCs. The results of western blot analysis revealed that MIF induced a pronounced increase in the Akt and mTOR phosphorylation levels in a time-dependent manner, with a peak at 60-90 min (Fig. 5A and B). However, in the cells treated with a PI3K inhibitor (LY294002) or the Akt inhibitor (MK-2206) prior to the addition of MIF, the Akt and mTOR phosphorylation levels were significantly decreased (Fig. 5D and E). These data suggest that MIF regulates CSC proliferation through the PI3K/Akt/mTOR pathway. 

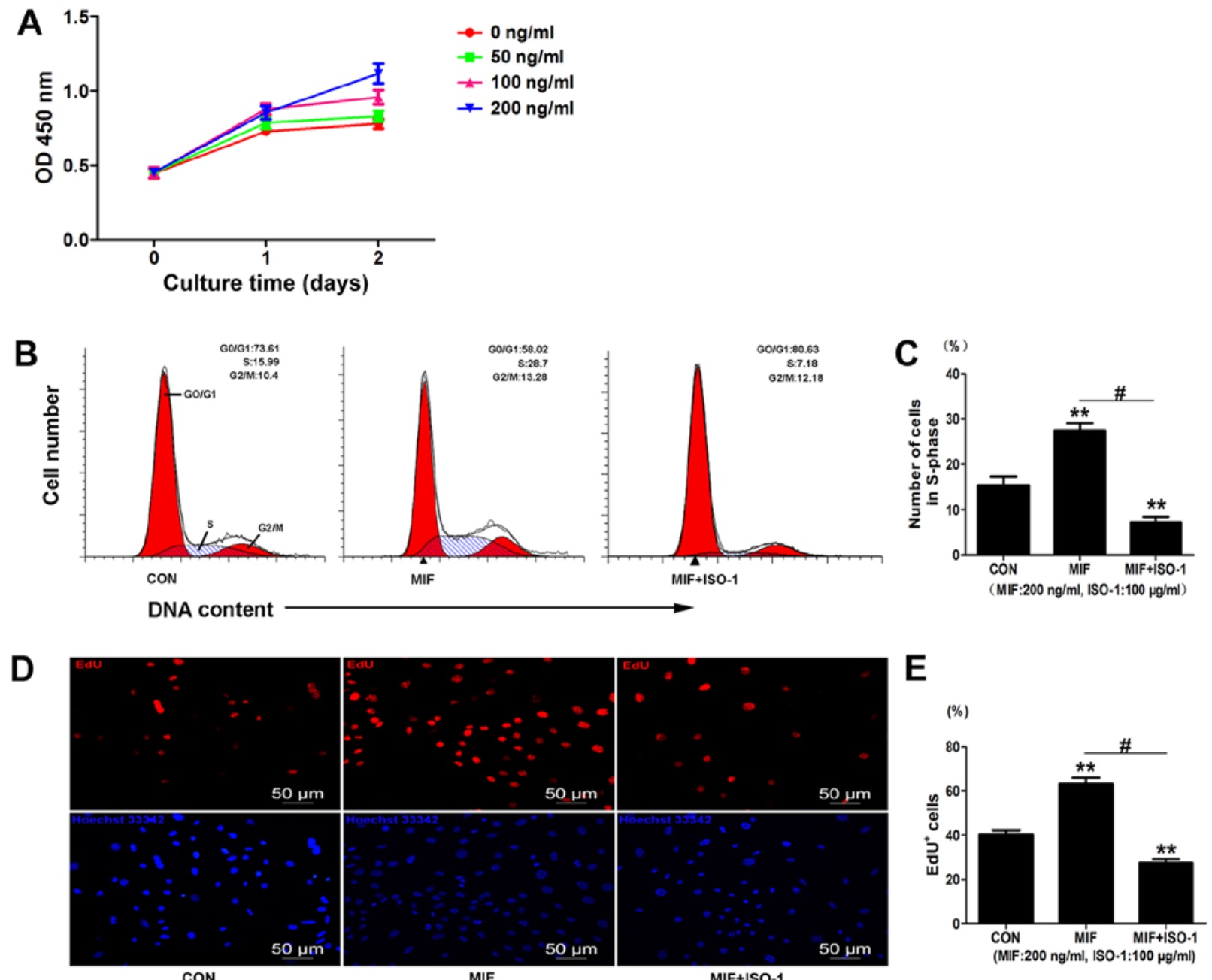

Figure 3. Macrophage migration inhibitory factor (MIF) promotes cardiac stem cell (CSC) proliferation. (A) MIF affects CSC viability in a dose-dependent manner. Cells were cultured with various concentrations of MIF in 96-well plates at a density of $5 \times 10^{3}$ cells/well. After 1 or 2 days in culture, cell viability was measured by CCK-8 assay. (B and C) Flow cytometric analysis of CSCs cultured in the presence of MIF (200 ng/ml) or ISO-1 (100 $\mu \mathrm{g} / \mathrm{ml})$. After 2 days, the percentage of cells in the S-phase was increased in the MIF treatment group compared to the control, and decreased in the ISO-1 treatment group. (D and E) MIF treatment increased EdU incorporation by CSCs. Cells were treated with MIF $(200 \mathrm{ng} / \mathrm{ml})$ or ISO-1 $(100 \mu \mathrm{g} / \mathrm{ml})$ for 1 day and then cultured for $2 \mathrm{~h}$ in medium with $50 \mu \mathrm{M}$ EdU. Cells were fixed, permeabilized and stained with the Apollo ${ }^{\circledast}$ reaction cocktail and Hoechst 33342 . Data in (A, C and E) are the means \pm SD of 3 independent experiments $(n=3){ }^{*}{ }^{*} p<0.01$ vs. control, ${ }^{*} \mathrm{p}<0.01$ indicates MIF + ISO-1 vs. MIF.

There is evidence to suggest that MIF also activates AMPK to protect cardiomyocytes from ischemic heart disease (18) and promotes the survival and proliferation of neural stem/progenitor cells (22). Thus, in this study, we examined the effects of MIF on the phosphorylation of AMPK in CSCs by western blot analysis. The results revealed that MIF also induced a marked increase in AMPK phosphorylation in a time-dependent manner, with a peak at 30-90 min (Fig. 5C). Following the knockdown of CD74, the activation of AMPK was significantly inhibited (Fig. 5F).

To further confirm that MIF acts through the PI3K/Akt/ mTOR and AMPK pathways to regulate CSC proliferation, the cells were treated with a PI3K inhibitor (LY294002), Akt inhibitor (MK-2206) and the AMPK inhibitor (compound C) prior to the addition of MIF. EdU assay revealed that all the inhibitors markedly inhibited MIF-induced cell proliferation (Fig. 7), which was consistent with the effects of transient CD74 knockdown.
To determine whether CD74 mediates MIF-induced $\mathrm{PI} 3 \mathrm{~K} / \mathrm{Akt} / \mathrm{mTOR}$ and AMPK activation in CSCs, we knocked down CD74 in the CSCs. The results of western blot analysis revealed that CD74 knockdown significantly decreased the levels of phosphorylated Akt, mTOR and AMPK compared to the control cells (Fig. 5D-F).

Effects of MIF on endothelial differentiation. CSCs can differentiate into cardiomyocytes, smooth muscle cells and endothelial cells under certain conditions (35). Previous studies have indicated that MIF can promote angiogenesis in teratoma and corneal tissues $(36,37)$. Akt phosphorylation plays an important role in BM-MSC differentiation into endothelial cells (38). Thus, we examined whether MIF regulates CSC differentiation into endothelial cells. We cultured the CSCs with MIF $(200 \mathrm{ng} / \mathrm{ml})$ for 7 days, and then removed the growth factors and MIF, and allowed the cells to grow for an additional 7 days. We found that the MIF-treated CSCs expressed significant amounts of 
A
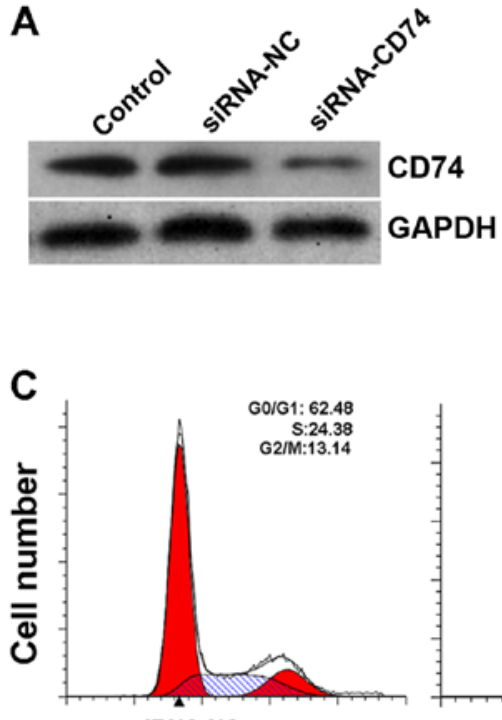

SiRNA-NC DNA content

E

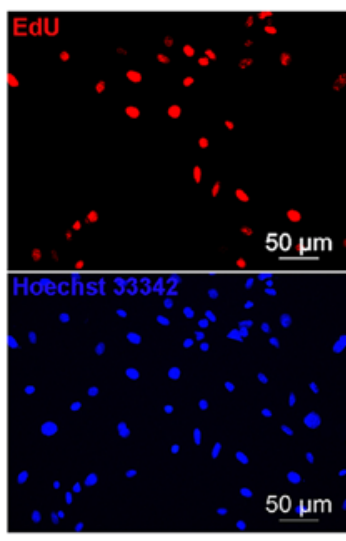

SIRNA-NC
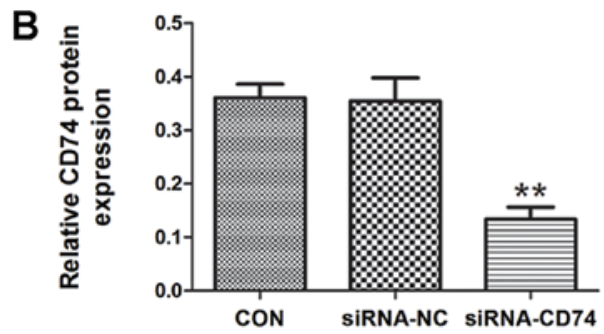

D

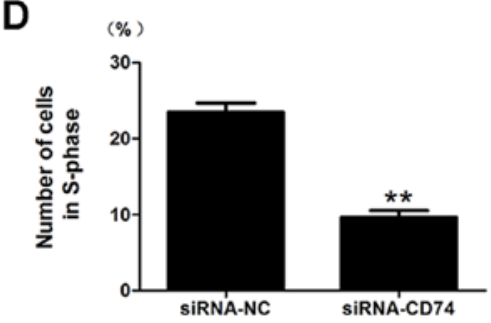

Figure 4. Macrophage migration inhibitory factor (MIF) promotes CD74-dependent cardiac stem cell (CSC) proliferation. (A and B) CSCs were transfected with a specific siRNA against CD74 (siRNA-CD74) or transfected with a negative control siRNA (siRNA-NC). Knockdown efficiency was examined by western blot analysis. (C and D) CSCs in which CD74 was knocked down were treated with MIF (200 ng/ml) for $48 \mathrm{~h}$. Flow cytometric analysis was used to detect the cell cycle, and the percentage of cells in the $\mathrm{S}$ phase decreased in the siRNA-CD74 group compared with the siRNA-NC group. (E and F) siRNAtransfected CSCs were treated with MIF (200 ng/ml) for $24 \mathrm{~h}$ and were cultured for additional $2 \mathrm{~h}$ in medium with $50 \mu \mathrm{M}$ EdU. Cells were fixed, permeabilized and stained with the Apollo ${ }^{\circledR}$ reaction cocktail and Hoechst 33342 . Data in $\left(B, D\right.$ and F) are the means \pm SD of 3 independent experiments $(\mathrm{n}=3)$. ${ }^{* *}$ p $<0.01$ vs. control or siRNA-NC.

VEGF and vWF compared to the controls (Fig. 6A-C), and the MIF-treated CSCs formed tubes in Matrigel paralleled with the positive control cells, the HUVECs (Fig. 6D and F); these results suggest that MIF-treated CSCs can differentiate into endothelial cells. However, the CSCs in which CD74 was knocked down, or the CSCs treated with MK-2206 (Akt inhibitor) could cannot differentiate into endothelial cells (data not shown). Thus, MIF may promote CSC differentiation into endothelial cells through the activatwion of the Akt pathway.

\section{Discussion}

In the present study, we firstly isolated and identify cardiac stem cells and we then demonstrated that CSCs secrete the pleiotropic cytokine, MIF, to promote their survival and proliferation. MIF also promoted CSC differentiation into endothelial cells. We further found that MIF exerted its effects on the CSCs through the MIF receptor CD74 expressed in CSCs, suggesting that MIF can maintain CSC self-renewal and differentiation capacity through autocrine and/or paracrine mechanisms. These findings suggest that treatment with MIF may be prove to be an effective strategy for the treatment of heart diseases, including myocardial infarction and heart failure, by activating native resident CSCs.

In our experiments, the used cells were positive for thye stem cell marker, CD117, and negative for CD45, CD34 and KDR, thus excluding contaminated cells, mainly hematopoietic lineage cells containing blood cell lineage precursors, mast cells, endothelial cells and endothelial progenitor cells $(7,39)$. The results of immunofluorescence staining revealed that our isolated cells expressed early cardiac transcription factors and can differentiate into 3 main cardiac lineages. These results suggested that the cells were indeed stem cells of cardiac origin.

Myocardial infarction and related heart failure are the leading cause of mortality worldwide. However, the ability of stem cells to restore heart function is encouraging and inspiring (40). Urbanek et al previously reported that the number of CSCs in 

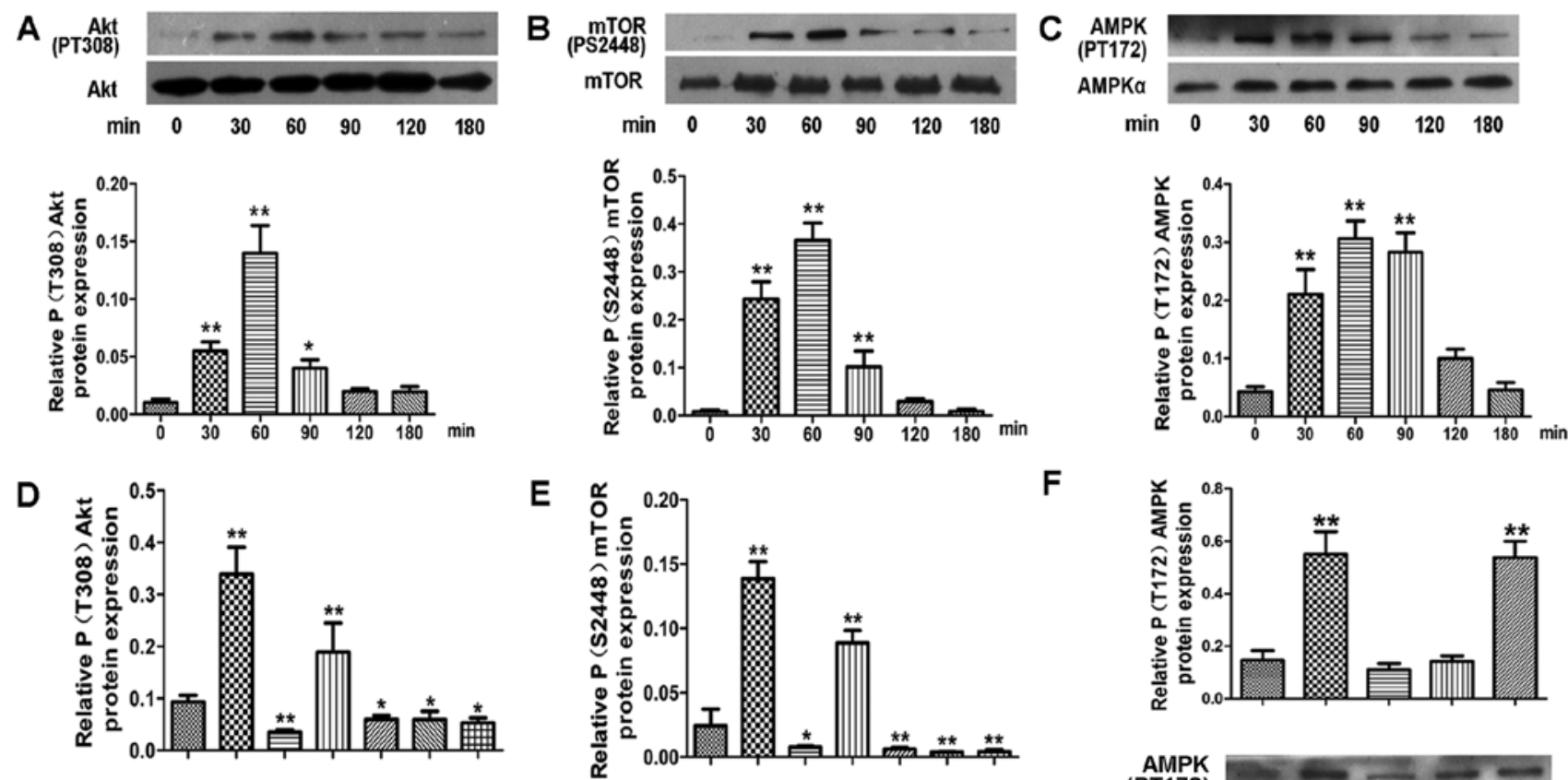

$\mathbf{F}$
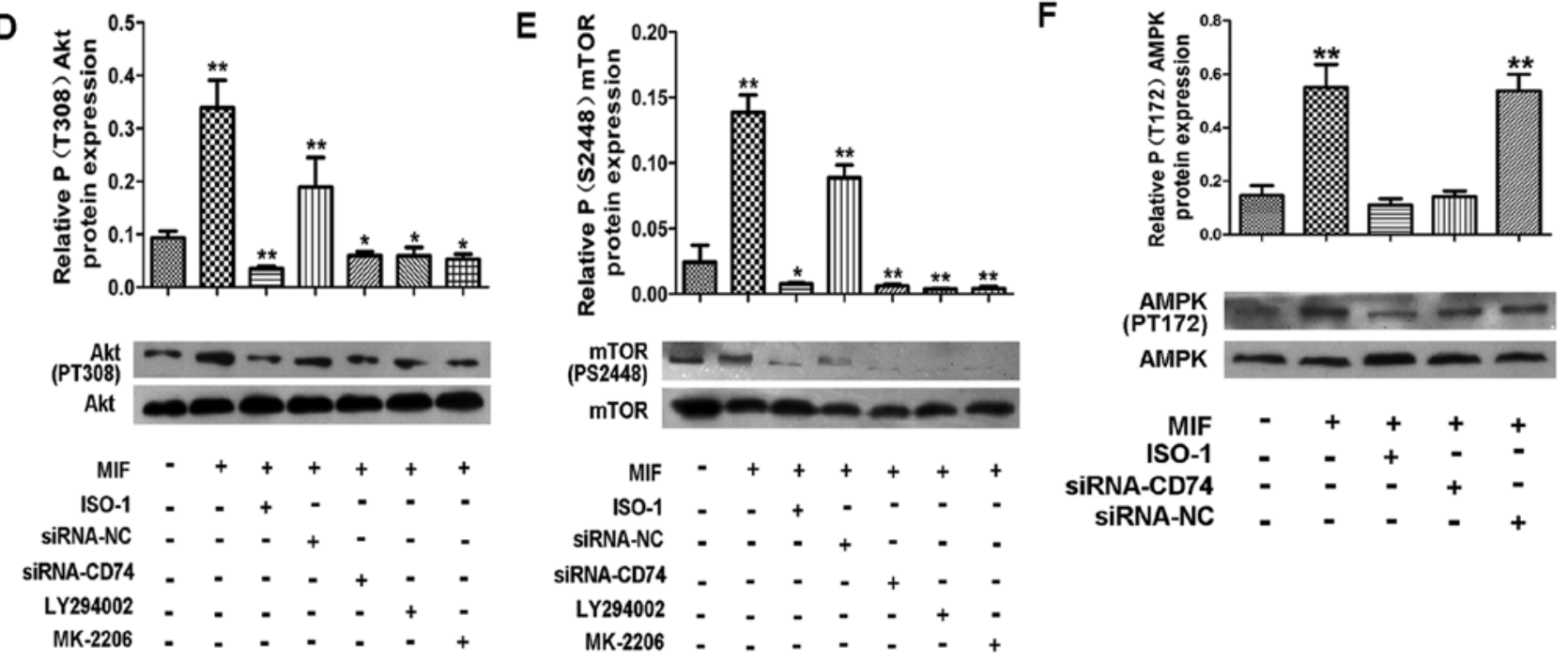

Figure 5. Macrophage migration inhibitory factor (MIF) activates the PI3K/Akt/mTOR pathway and adenosine monophosphate-activated protein kinase (AMPK) in cardiac stem cells (CSCs). (A-C) Following treatment wiht MIF (200 ng/ml) for various periods of time, the cells were harvested and western blot analyses were performed to compare the changes in the levels of (A) phospho-Akt (T308), (B) phospho-mTOR(S2448), and (C) phospho-AMPK(T172). (D-E) CSCs were pre-treated with LY294002 (PI3K inhibitor, $25 \mathrm{mM}$ ) or MK-2206 (Akt inhibitor, $20 \mathrm{mM}$ ) for $90 \mathrm{~min}$, or transfected with siRNA-NC or siRNA-CD74 for $72 \mathrm{~h}$. MIF (200 ng/ml) was then added in the presence of each drug followed by culture for an additional $1 \mathrm{~h}$. (D) Akt and phospho-Akt (T308), (E) mTOR and phosphomTOR (S2448), and (F) AMPK and phospho-AMPK (T172). Data are the means \pm SD of 3 independent experiments $(\mathrm{n}=3)$. ${ }^{*} \mathrm{p}<0.05$ and ${ }^{* * *} \mathrm{p}<0.01 \mathrm{vs.} \mathrm{control.}$

normal heart atria is approximately 5 -fold higher than in the left ventricle, but in ischemic heart failure, the number of multipotent CSCs in the left ventricle increases to become greater than that in the atria (11). These data suggest that in the injured heart, there must be a substance that promotes CSC growth and/or migration. Previous studies have found that cardiomyocytes secrete MIF, which exerts anti-senescence, antioxidant and antiapoptotic effects on cardiomyocytes $(41,42)$. In this study, we found that CSCs secreted MIF and MIF promoted CSC survival and proliferation. These results suggest that MIF secreted by CSCs or injured cardiomyocytes may contribute to the increased number of CSCs in the injured left ventricle. Furthermore, we found that MIF regulated cell cycle progression by promoting the G1/S-phase transition, thereby controlling cell proliferation, thus improving the number of CSCs in the injured heart. Our study also indicated that the inhibition of MIF or CD74 inhibited or delayed the G1/S-phase transition.

Proangiogenic therapy was originally a promising strategy for the treatment of acute myocardial infarction, although clinical trials have failed to elicit the expected effects $(43,44)$. HilfikerKleiner et al found that the endothelial differentiation capacity of c-kit ${ }^{+}$resident stem cells was severely impaired in models of heart failure (45). However, little is known about the regulatory factors within the cardiac microenvironment, particularly during heart failure and myocardial infarction. Certain studies have suggested that circulating MIF levels and MIF levels within the local damaged myocardium are both increased. A number of studies have shown that MIF can promote angiogenesis in teratomas, corneal tissue and heart by recruiting stem cells or disrupting macrophage polarization $(36,37)$. In the present study, we found that MIF promoted CSCs to express VEGF and differentiate into endothelial cells. Treatment with ISO-1 or CD74 knockdown inhibited the effects of MIF on CSCs. At the same time, we performed a tube formation assay to examine the angiogenic effect of MIF in vitro and found that the CSCs treated with MIF formed tube structures in parallel with the HUVECs, suggesting that MIF may promote neovascularization following myocardial infarction by promoting CSC differentiation into endothelial cells. Neovascularization can often provide enough oxygen to support cell growth and function. This effect further illustrated that MIF may contribute to reverse heart dysfunction and decrease infarct size. Whether MIF promotes neovascularization by regulating other progenitor cells or other mechanisms requires further study. 

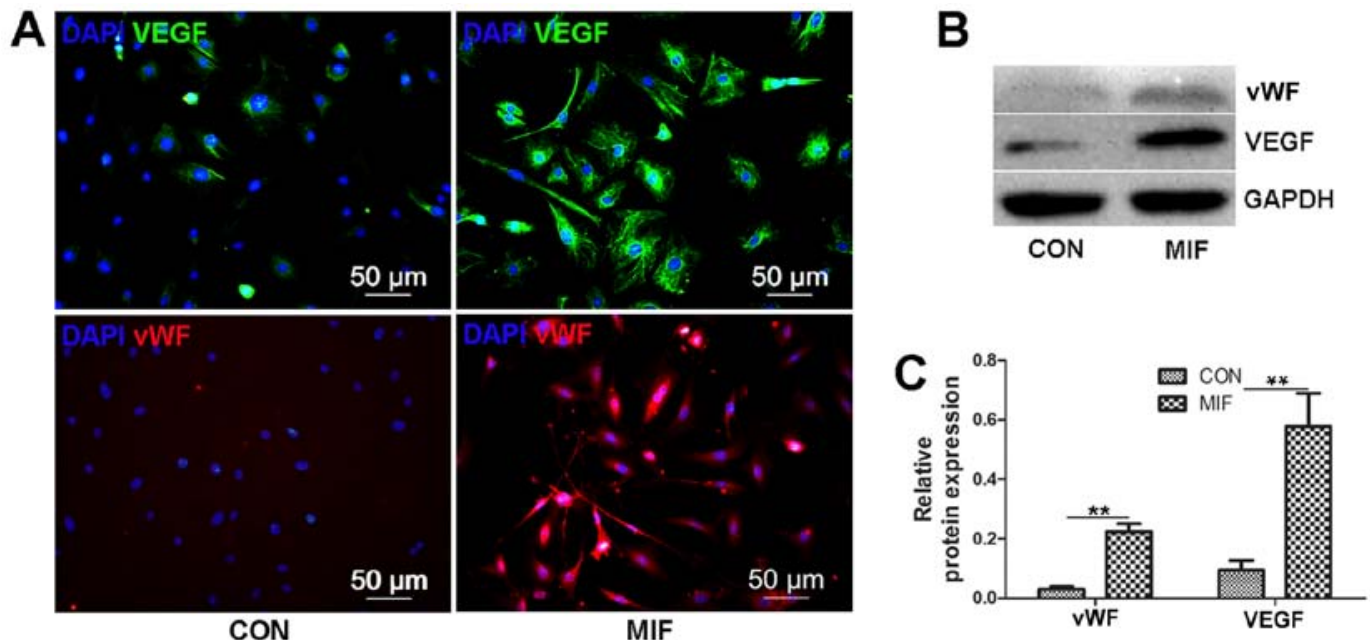

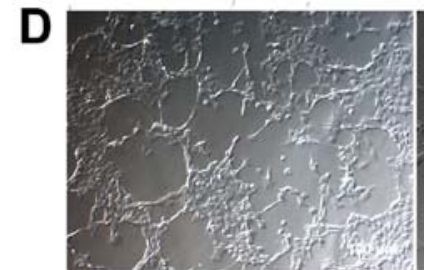

CON

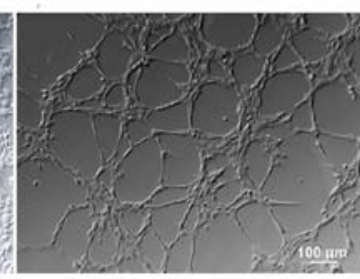

CSC-ECs

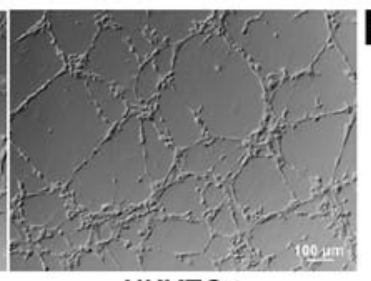

HUVECS

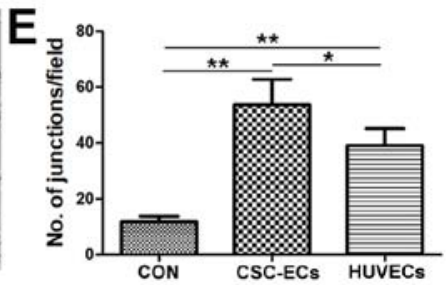

CON CSC-ECs HUV́ECS

Figure 6. Macrophage migration inhibitory factor (MIF) promotes the expression of vascular endothelial growth factor (VEGF) in cardiac stem cells (CSCs) and their differentiation into endothelial cells. CSCs were cultured in growth medium or growth medium with MIF (200 ng/ml) for 7 days. Growth factors and MIF were removed, and the cells were cultured for an additional 7 days. (A) Differentiated cells were fixed, permeabilized and stained with rabbit anti-VEGF antibody and DAPI, or rabbit anti-vWF antibody and DAPI. Strongly significant changes were observed in the percentages of DAPI-positive cells labeled with an endothelial cell marker (vWF). (B and C) At the same time, cells were harvested and western blot analyses were performed to compare the changes in VEGF and vWF expression. HUVECs and CSCs treated with or without MIF were seeded in Matrigel-coated 48-well plates. (D and E) The number of tube junctions/field was counted. Similar independent experiments were repeated 3 times $(n=3)$. ${ }^{*}<<0.05$ and ${ }^{* *} p<0.01$ vs. control.
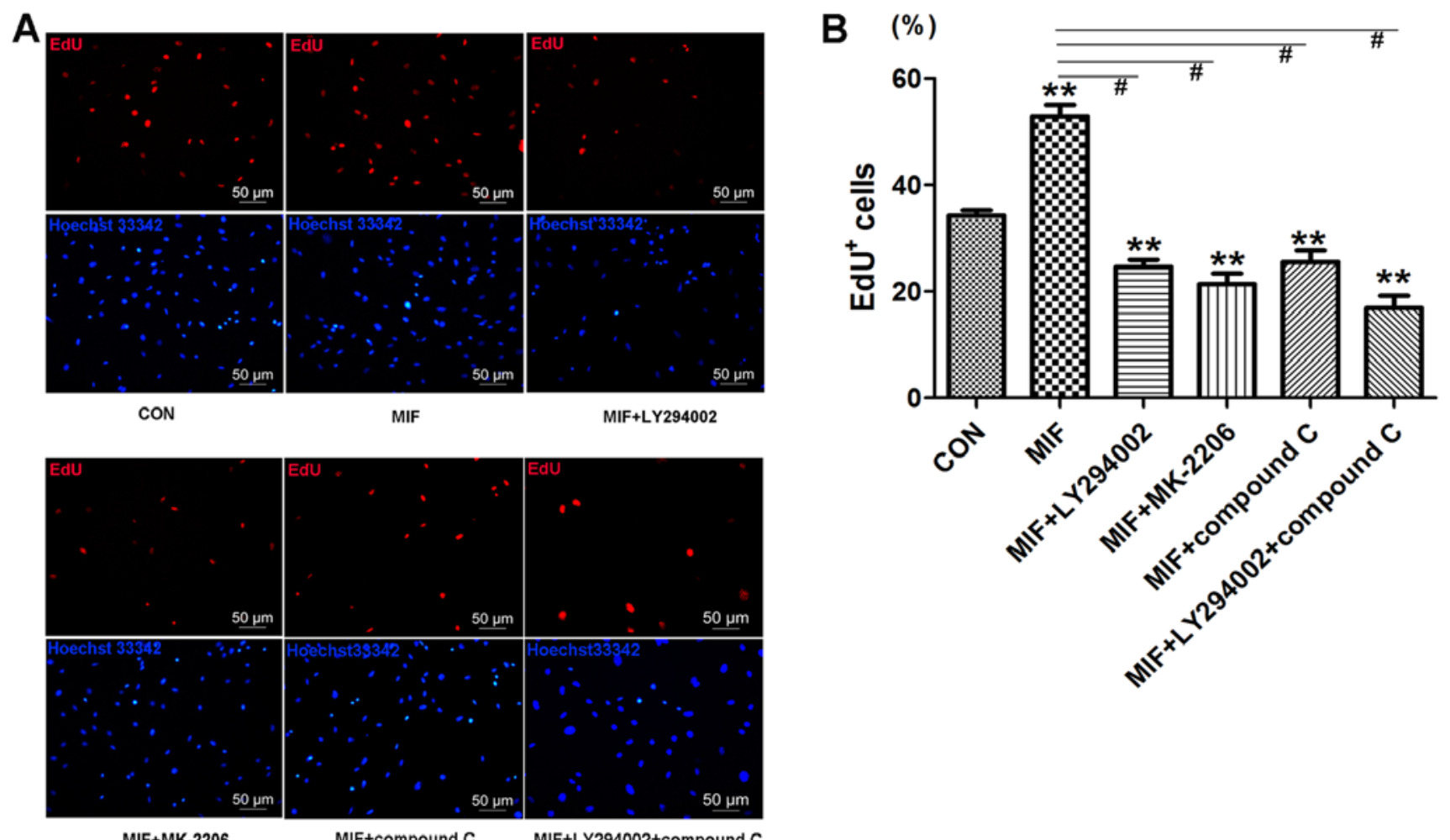

Figure 7. PI3K/Akt/mTOR pathway and AMPK inhibition blocks macrophage migration inhibitory factor (MIF)-induced cardiac stem cell (CSC) proliferation (A) CSCs were pre-treated with the PI3K inhibitor, LY294002, the AKT inhibitor, MK-2206, or the AMPK inhibitor, compound C for 90 min and then co-treated with MIF $(200 \mathrm{ng} / \mathrm{ml})$ for $48 \mathrm{~h}$. Cells were cultured for a further $2 \mathrm{~h}$ in medium with $50 \mu \mathrm{M}$ EdU. Cells were fixed, permeabilized and stained with the Apollo ${ }^{\circledR}$ reaction cocktail and Hoechst 33342. Data in (B) are the means \pm SD of 3 independent experiments ( $\mathrm{n}=3$ ). ${ }^{* *} \mathrm{p}<0.01$ vs. control, ${ }^{*} \mathrm{p}<0.01 \mathrm{vs.}$ MIF. 
The PI3K/Akt/mTOR signaling pathway plays a central role in numerous cellular functions, including proliferation, adhesion, migration, invasion, metabolism and survival (27). It is activated by a number of inflammatory cytokines and agents, including lipopolysaccharide (LPS) and phorbolmyristate acetate (PMA) (46). Our results demonstrated that exogenous MIF activates the PI3K/Akt/mTOR pathway through its receptor $\mathrm{CD} 74$. It has been demonsgtrated that the activation of the PI3K/Akt pathway in cancer cells can also modulate the expression of hypoxia-inducible factor-1 (HIF-1) and other angiogenic factors, such as nitric oxide and angiopoietins, which function to increase VEGF production (47). VEGF has been identified as an angiogenic factor and survival factor that stimulates angiogenesis and protects cells from stresses (48). In this study, we found that MIF promoted the expression of VEGF in CSCs and CSC differentiation into endothelial cells, suggesting that MIF improves cardiac function by promoting angiogenesis. Our results are consistent with the pro-angiogenic effects of MIF and PI3K/Akt/mTOR pathway activation in other organs, including tumors and corneal tissue $(49,50)$. However, whether MIF regulates additional angiogenic factors remains unclear.

AMPK orchestrates the regulation of both glycolysis and glucose uptake and protects the heart against ischemic injury and apoptosis (51). There is evidence to suggest that MIF also plays a role in the stimulation of the AMPK pathway to protect the heart in ischemic heart disease (18) and promote the survival and proliferation of neural stem/progenitor cells (22). In this study, we also found that MIF promotes the phosphorylation of AMPK, and that AMPK inhibition partly blocked the proliferation of CSC induced by MIF. These results suggest that MIF promotes the proliferation of CSCs partly through the activation of AMPK. As MIF can stimulate many signaling pathways, we cannot rule out other mechanisms contributing to effects of MIF on resident cardiac stem cells, such as JNK inhibition.

Taken together, our data suggest that MIF promotes CSC proliferation and endothelial differentiation, suggesting that MIF not only increased the quantity, but also improved the function of CSCs. This may be one explanation for why in ischemic heart failure, the number of multipotent cardiac stem cells in the left ventricle is higher than that in the atria and MIF can improve heart function. However, MIF plays a potential role in inflammation. It has been demonstrated that MIF provokes the inflammatory response following myocardial infarction to remove cellular debris and facilitate healing, whereas excessive inflammation leads to adverse cardiac remodeling (52). It has also been demonstrated that the role of MIF differs depending on the source of MIF. White et al found that non-leukocyte MIF enhanced myocardial healing, whereas leukocyte MIF enhanced damage (34). Koga et al found that the intracellular overexpression of MIF had oxidoreductase effects, however, exogenous MIF did not display such an effect (41). These may be one of the reasons why many studies obtained unexpected results regarding the role of MIF in post-infarct healing and cardiac remodeling (53). These suggest that further studies are warranted in order to develop novel therapeutic methods which preserve the benign effects of MIF to provide cardioprotection in ischemic heart disease without activating MIF pro-inflammatory activity. For instance, Luedike et al found that the S-nitros(yl)ation modification of MIF enhanced the cytoprotective effects in myocardial reperfusion injury (54).
Furthermore, it has been demonstrated that MIF acts as an oxidoreductase to maintain intracellular redox homeostasis in cardiomyocytes (41). In the present study, we cannot completely rule out the possibility that antioxidant or other effects of MIF compensate for its protective effects on CSCs.

In conclusion, the results presented in this study demonstrate that CSCs express MIF and its receptor CD74. We also found that MIF affected cell survival, cell cycle progression, proliferation and differentiation, by promoting the activation of the PI3K/Akt/mTOR and AMPK pathways through CD74. Our findings support the hypothesis that MIF may be a novel potential therapeutic factor for the treatment for degenerative heart disorders through CSC activation.

\section{Acknowledgements}

We would like to thank Dr Hulun Li and Dr Wei Liu for their expert assistance with the experimental design and excellent technical assistance. This study was supported by grants from the National Natural Science Foundation of China (to B.Y., grant nos. 81171430 and 81330033) and the Key Laboratory of Myocardial Ischemia Mechanism and Treatment (Harbin Medical University), Ministry of Education (to J.C., grant no. KF201402).

\section{References}

1. Tang XL, Rokosh G, Sanganalmath SK, Yuan F, Sato H, Mu J, Dai S, Li C, Chen N, Peng Y, et al: Intracoronary administration of cardiac progenitor cells alleviates left ventricular dysfunction in rats with a 30-day-old infarction. Circulation 121: 293-305, 2010.

2. Chimenti I, Smith RR, Li TS, Gerstenblith G, Messina E, Giacomello A and Marbán E: Relative roles of direct regeneration versus paracrine effects of human cardiosphere-derived cells transplanted into infarcted mice. Circ Res 106: 971-980, 2010.

3. Rufaihah AJ, Haider HK, Heng BC, Ye L, Tan RS, Toh WS, Tian XF, Sim EK and Cao T: Therapeutic angiogenesis by transplantation of human embryonic stem cell-derived CD133 ${ }^{+}$ endothelial progenitor cells for cardiac repair. Regen Med 5: 231-244, 2010.

4. Leri A, Kajstura J and Anversa P: Role of cardiac stem cells in cardiac pathophysiology: A paradigm shift in human myocardial biology. Circ Res 109: 941-961, 2011.

5. Williams AR and Hare JM: Mesenchymal stem cells: Biology, pathophysiology, translational findings, and therapeutic implications for cardiac disease. Circ Res 109: 923-940, 2011.

6. Oskouei BN, Lamirault G, Joseph C, Treuer AV, Landa S, Da Silva J, Hatzistergos K, Dauer M, Balkan W, McNiece I and Hare JM:: Increased potency of cardiac stem cells compared with bone marrow mesenchymal stem cells in cardiac repair. Stem Cells Transl Med 1: 116-124, 2012.

7. Ellison GM, Vicinanza C, Smith AJ, Aquila I, Leone A, Waring CD, Henning BJ, Stirparo GG, Papait R, Scarfò M, et al: Adult c-kit(pos) cardiac stem cells are necessary and sufficient for functional cardiac regeneration and repair. Cell 154: 827-842, 2013.

8. Chimenti C, Kajstura J, Torella D, Urbanek K, Heleniak H, Colussi C, Di Meglio F, Nadal-Ginard B, Frustaci A, Leri A, et al: Senescence and death of primitive cells and myocytes lead to premature cardiac aging and heart failure. Circ Res 93: 604-613, 2003.

9. Dimmeler S and Leri A: Aging and disease as modifiers of efficacy of cell therapy. Circ Res 102: 1319-1330, 2008.

10. Urbanek K, Quaini F, Tasca G, Torella D, Castaldo C, NadalGinard B, Leri A, Kajstura J, Quaini E and Anversa P: Intense myocyte formation from cardiac stem cells in human cardiac hypertrophy. Proc Natl Acad Sci USA 100: 10440-10445, 2003.

11. Urbanek K, Torella D, Sheikh F, De Angelis A, Nurzynska D, Silvestri F, Beltrami CA, Bussani R, Beltrami AP, Quaini F, et al: Myocardial regeneration by activation of multipotent cardiac stem cells in ischemic heart failure. Proc Natl Acad Sci USA 102: 8692-8697, 2005. 
12. Burger-Kentischer A, Goebel H, Seiler R, Fraedrich G, Schaefer HE, Dimmeler S, Kleemann R, Bernhagen J and Ihling C: Expression of macrophage migration inhibitory factor in different stages of human atherosclerosis. Circulation 105: 1561-1566, 2002.

13. Calandra T, Echtenacher B, Roy DL, Pugin J, Metz CN, Hültner L, Heumann D, Männel D, Bucala R and Glauser MP: Protection from septic shock by neutralization of macrophage migration inhibitory factor. Nat Med 6: 164-170, 2000.

14. Morand EF, Bucala R and Leech M: Macrophage migration inhibitory factor: An emerging therapeutic target in rheumatoid arthritis. Arthritis Rheum 48: 291-299, 2003.

15. Calandra $\mathrm{T}$ and Roger $\mathrm{T}$ : Macrophage migration inhibitory factor: A regulator of innate immunity. Nat Rev Immunol 3: 791-800, 2003.

16. Morand EF, Leech M and Bernhagen J: MIF: A new cytokine link between rheumatoid arthritis and atherosclerosis. Nat Rev Drug Discov 5: 399-410, 2006.

17. Yu CM, Lai KW, Chen YX, Huang XR and Lan HY: Expression of macrophage migration inhibitory factor in acute ischemic myocardial injury. J Histochem Cytochem 51: 625-631, 2003

18. Miller EJ, Li J, Leng L, McDonald C, Atsumi T, Bucala R and Young LH: Macrophage migration inhibitory factor stimulates AMP-activated protein kinase in the ischaemic heart. Nature 451: 578-582, 2008

19. Qi D, Hu X, Wu X, Merk M, Leng L, Bucala R and Young LH Cardiac macrophage migration inhibitory factor inhibits JNK pathway activation and injury during ischemia/reperfusion. J Clin Invest 119: 3807-3816, 2009.

20. Stumptner-Cuvelette $P$ and Benaroch P: Multiple roles of the invariant chain in MHC class II function. Biochim Biophys Acta 1542: 1-13, 2002.

21. Leng L, Metz CN, Fang Y, Xu J, Donnelly S, Baugh J, Delohery T, Chen Y, Mitchell RA and Bucala R: MIF signal transduction initiated by binding to CD74. J Exp Med 197: 1467-1476, 2003.

22. Ohta S, Misawa A, Fukaya R, Inoue S, Kanemura Y, Okano H, Kawakami Y and Toda M: Macrophage migration inhibitory factor (MIF) promotes cell survival and proliferation of neural stem/progenitor cells. J Cell Sci 125: 3210-3220, 2012.

23. Schrans-Stassen B, Lue H, Sonnemans D, Bernhagen J and Post M: Stimulation of vascular smooth muscle cell migration by macrophage migration inhibitory factor. Antioxid Redox Signal 7: 1211-1216,2005.

24. Xiong CJ, Huang B, Zhou Y, Cun YP, Liu LT, Wang J, Li CQ, Pan $\mathrm{Y}$ and Wang H: Macrophage migration inhibitory factor inhibits the migration of cartilage end plate-derived stem cells by reacting with CD74. PLoS One 7: e43984, 2012.

25. Xia W, Zhang F, Xie C, Jiang M and Hou M: Macrophage migration inhibitory factor confers resistance to senescence through CD74-dependent AMPK-FOXO3a signaling in mesenchymal stem cells. Stem Cell Res Ther 6: 82, 2015.

26. Palumbo S, Tsai TL and Li WJ: Macrophage migration inhibitory factor regulates AKT signaling in hypoxic culture to modulate senescence of human mesenchymal stem cells. Stem Cells Dev 23: 852-865, 2014

27. Ciuffreda L, Di Sanza C, Incani UC and Milella M: The mTOR pathway: A new target in cancer therapy. Curr Cancer Drug Targets 10: 484-495,2010

28. Gao N, Zhang Z, Jiang BH and Shi X: Role of PI3K/AKT/mTOR signaling in the cell cycle progression of human prostate cancer. Biochem Biophys Res Commun 310: 1124-1132, 2003.

29. Morgensztern D and McLeod HL: PI3K/Akt/mTOR pathway as a target for cancer therapy. Anticancer Drugs 16: 797-803, 2005.

30. Smith AJ, Lewis FC, Aquila I, Waring CD, Nocera A, Agosti V, Nadal-Ginard B, Torella D and Ellison GM: Isolation and characterization of resident endogenous $\mathrm{c}-\mathrm{Kit}^{+}$cardiac stem cells from the adult mouse and rat heart. Nat Protoc 9: 1662-1681, 2014.

31. Liu J, Wang Y, Du W, Liu W, Liu F, Zhang L, Zhang M, Hou M, Liu K, Zhang S and Yu B: Wnt1 inhibits hydrogen peroxideinduced apoptosis in mouse cardiac stem cells. PLoS One 8: e58883, 2013

32. Hou M, Cui J, Liu J, Liu F, Jiang R, Liu K, Wang Y, Yin L, Liu W and Yu B: Angiopoietin-like 4 confers resistance to hypoxia/serum deprivation-induced apoptosis through PI3K/Akt and ERK1/2 signaling pathways in mesenchymal stem cells. PLoS One 9: e85808, 2014

33. Chen J, Baydoun AR, Xu R, Deng L, Liu X, Zhu W, Shi L, Cong X, Hu S and Chen X: Lysophosphatidic acid protects mesenchymal stem cells against hypoxia and serum deprivationinduced apoptosis. Stem Cells 26: 135-145, 2008.

34. White DA, Su Y, Kanellakis P, Kiriazis H, Morand EF, Bucala R, Dart AM, Gao XM and Du XJ: Differential roles of cardiac and leukocyte derived macrophage migration inhibitory factor in inflammatory responses and cardiac remodelling post myocardial infarction. J Mol Cell Cardiol 69: 32-42, 2014.
35. Beltrami AP, Urbanek K, Kajstura J, Yan SM, Finato N, Bussani R, Nadal-Ginard B, Silvestri F, Leri A, Beltrami CA and Anversa P: Evidence that human cardiac myocytes divide after myocardial infarction. N Engl J Med 344: 1750-1757, 2001.

36. Usui T, Yamagami S, Kishimoto S, Seiich Y, Nakayama T and Amano S: Role of macrophage migration inhibitory factor in corneal neovascularization. Invest Ophthalmol Vis Sci 48: 3545-3550, 2007

37. Wang X, Chen T, Leng L, Fan J, Cao K, Duan Z, Zhang X, Shao C, Wu M, Tadmori I, et al: MIF produced by bone marrow-derived macrophages contributes to teratoma progression after embryonic stem cell transplantation. Cancer Res 72: 2867-2878, 2012.

38. Chu L, Hao H, Luo M, Huang Y, Chen Z, Lu T, Zhao X, Verfaillie CM, Zweier JL and Liu Z: Ox-LDL modifies the behaviour of bone marrow stem cells and impairs their endothelial differentiation via inhibition of Akt phosphorylation. J Cell Mol Med 15: 423-432, 2011.

39. Zhou Y, Pan P, Yao L, Su M, He P, Niu N, McNutt MA and Gu J: CD117-positive cells of the heart: progenitor cells or mast cells? J Histochem Cytochem 58: 309-316, 2010.

40. Moran AE, Forouzanfar MH, Roth GA, Mensah GA, Ezzati M, Flaxman A, Murray CJ and Naghavi M: The global burden of ischemic heart disease in 1990 and 2010: the Global Burden of Disease 2010 study. Circulation 129: 1493-1501, 2014.

41. Koga K, Kenessey A, Powell SR, Sison CP, Miller EJ and Ojamaa K: Macrophage migration inhibitory factor provides cardioprotection during ischemia/reperfusion by reducing oxidative stress. Antioxid Redox Signal 14: 1191-1202, 2011.

42. Ma H, Wang J, Thomas DP, Tong C, Leng L, Wang W, Merk M, Zierow S, Bernhagen J, Ren J, et al: Impaired macrophage migration inhibitory factor-AMP-activated protein kinase activation and ischemic recovery in the senescent heart. Circulation 122: 282-292, 2010.

43. Losordo DW and Dimmeler S: Therapeutic angiogenesis and vasculogenesis for ischemic disease: part II: cell-based therapies. Circulation 109: 2692-2697, 2004.

44. Tongers J, Losordo DW and Landmesser U: Stem and progenitor cell-based therapy in ischaemic heart disease: Promise, uncertainties, and challenges. Eur Heart J 32: 1197-1206, 2011.

45. Hilfiker-Kleiner D, Hilfiker A, Fuchs M, Kaminski K, Schaefer A Schieffer B, Hillmer A, Schmiedl A, Ding Z, Podewski E, et al: Signal transducer and activator of transcription 3 is required for myocardial capillary growth, control of interstitial matrix deposition, and heart protection from ischemic injury. Circ Res 95: $187-195,2004$

46. Salh B, Wagey R, Marotta A, Tao JS and Pelech S: Activation of phosphatidylinositol 3-kinase, protein kinase B, and p70 S6 kinases in lipopolysaccharide-stimulated Raw 264.7 cells: Differential effects of rapamycin, Ly294002, and wortmannin on nitric oxide production. J Immunol 161: 6947-6954, 1998.

47. Karar J and Maity A: PI3K/AKT/mTOR pathway in angiogenesis. Front Mol Neurosci 4: 51, 2011

48. Byrne AM, Bouchier-Hayes DJ and Harmey JH: Angiogenic and cell survival functions of vascular endothelial growth factor (VEGF). J Cell Mol Med 9: 777-794, 2005.

49. Choudhary S, Hegde P, Pruitt JR, Sielecki TM, Choudhary D, Scarpato K, Degraff DJ, Pilbeam CC and Taylor JA III: Macrophage migratory inhibitory factor promotes bladder cancer progression via increasing proliferation and angiogenesis. Carcinogenesis 34: 2891-2899, 2013.

50. Amin MA, Volpert OV, Woods JM, Kumar P, Harlow LA and Koch AE: Migration inhibitory factor mediates angiogenesis via mitogen-activated protein kinase and phosphatidylinositol kinase. Circ Res 93: 321-329, 2003.

51. Russell RR III, Li J, Coven DL, Pypaert M, Zechner C, Palmeri M, Giordano FJ, Mu J, Birnbaum MJ and Young LH: AMP-activated protein kinase mediates ischemic glucose uptake and prevents postischemic cardiac dysfunction, apoptosis, and injury. J Clin Invest 114: 495-503, 2004.

52. Dayawansa NH, Gao XM, White DA, Dart AM and Du XJ: Role of MIF in myocardial ischaemia and infarction: insight from recent clinical and experimental findings. Clin Sci (Lond) 127: 149-161, 2014.

53. Gao XM, Liu Y, White D, Su Y, Drew BG, Bruce CR, Kiriazis H, $\mathrm{Xu} \mathrm{Q}$, Jennings $\mathrm{N}$, Bobik A, et al: Deletion of macrophage migration inhibitory factor protects the heart from severe ischemia-reperfusion injury: A predominant role of anti-inflammation. J Mol Cell Cardiol 50: 991-999, 2011.

54. Luedike P, Hendgen-Cotta UB, Sobierajski J, Totzeck M, Reeh M, Dewor M, Lue H, Krisp C, Wolters D, Kelm M, et al: Cardioprotection through S-nitros(yl)ation of macrophage migration inhibitory factor. Circulation 125: 1880-1889, 2012. 